the "razor backs" of the past generation having given place to improved breeds. In northern Texas the best strains of Chester White, Essex, Berkshire, etc., are being propagated. In this connection it is noticeable that the immense enlargement of swine products, without any adequate evidence of equivalent decrease in the rate of home consumption, has only been accomplished by increase of average weight, or large increase of numbers in proportion to population.

A comparison of prices for 1876 with the present time shows the following, so far as the Boston market is conserned: Ham, superfine, spring, $\$ 4$ to $\$ 4.25$; good to fancy, $\$ 6$ to $\$$. March, $1878, \$ 4.25$ to $\$ 4.75$; good to fancy, $\$ 6.50$ to $\$ 8$. Pork, two years ago, that sold at $\$ 22.65$ to $\$ 22.80$, and $\$ 18.50$ to $\$ 21.50$, is now sold at $\$ 10$ to $\$ 10.50$, and $\$ 12$ to $\$ 14$ per barrel.

In the matter of dairy products, there is little or no difference in the prices that prevailed six years ago and now. Then New York and Vermont butter was quoted in March at 18 to 35 cents; cheese was a few cents higher, ranging from $14 \frac{1}{2}$ to $17 \frac{1}{2}$, against 12 and $14 \frac{1}{2}$ cents at the present time; while two years ago prices for these articles were a cent or two higher than the prevailing rates. Lard is now selling at $7 \frac{1}{2}$ to 8 cents, against 13 to $13 \frac{1}{2}$ cents in 1876 , and $9 \frac{1}{4}$ to 10 cents in 1872. The article of hay, of which there were produce in $187223,969,000$ tons, valued at $\$ 348,000$, 000 , sold in that year in Boston, in March, from $\$ 22$ to $\$ 32$ for Northern and Eastern, and $\$ 25$ to $\$ 30$ for Western choice. The quotations now stand at $\$ 20$ for fancy Northern, and $\$ 16$ and $\$ 19$ for other kinds. Two years ago Eastern and Northern hay was cheaper than it now is, having sold at from $\$ 13$ to $\$ 20$ per ton. The hay crop of 1876 was estimated at $30,867,000$ tons, valued at $\$ 300,000,000$. The crop of 1872 was estimated at $23,000,000$ tons, valued at $\$ 345,009,000$.

This subject of comparative prices might be pursued to an almost indefinite extent. Potatoes, for instance, the crop $1,381,000$ acres, and valued at $\$ 68,000,000$, were sold in that year at the rate of 90 to 95 cents per bushel for Early Rose and the same for Jackson Whites. The crop of last year was estimated at 124,000,000 bushels, grown on 1,741,000 acres, valued at $\$ 83,000,000$, while the prevailing prices range from 35 to 60 cents, according to quality. The average value per acre of the crop six years ago was $\$ 51.14$, last year $\$ 48.14$, the average price per bushel being $651 / 2$ cents. The apple crop has also varied a good deal, both in the quantities raised, the export demand, and the prices obtained. Although this is a nationalfruit, and has become an important article of export, yet the Government statistician has furnished no good data of facts respecting the trade in this article. Respecting jobbing prices, however, it appears that in 1872 prices for a good article ranged from $\$ 2.50$ to
$\$ 3$ for Western, and $\$ 2$ to $\$ 2.50$ for Eastern, as against $\$ 4.25$ and $\$ 5$ per barrel at the present time.

Not omitting some of the more material products that enter into the manufacture of textile goods, the ups and downs of the wool market afford a good study. In 1872 the range of prices was as follows: Picklock XXXOhio and Pennsylvania, 57 to 85 cents per pound; medium XX Ohio and Pennsylvania, 56 to 85 cents; Michigan, 52 to 82 cents; Western, 50 to 82 cents. In 1876 (at this season of the year) prices ranged from 38 to 521/2 cents for Ohio and Pennsylvania, 42 to 46 for Michigan, 35 to 47 for pulled, 42 to 65 for combing fieece, and 14 to 33 cents for California. Present quotations: Ohio and Pennsylvania, 42 to 43 cents for medium; Michigan, Wisconsin, etc., range from 38 to 40 cents; dium; Michigan, Wisconsin, etc., range from 38 to 40 cents;
and low and coarse fleeces from 34 to 37 cents per pound combing and delaine are nominal. The wool market is very dull at the present time.

Respecting the future prices for farm products the matter is enigmatical, but the hope is that a business revival may soon come and advance and strengthen prices for all kinds of produce, and thus enable the farmer to realize a fair profit and a good market.-Boston Cultivator.

\section{What Kills.}

In the school, as in the world, far more rust out than wear out. Study is most tedious and wearisome to those who study least. Drones always have the toughest time. Grumblers make poor scholars, and their lessons are uniformly " hard" and " too long." The time and thought expended in shirking would be ample to master their tasks. Sloth gormandizing, and worry kill their thousands, where overgormandizing, and worry kill their thousands, where over-
study harms one. The curse of Heaven rests on lazines study harms one. The curse of Heaven rests on laziness
and gluttony. By the very constitution of our being they are fitted to beget that torpor and despondency which chill the blood, deaden the nerves, enfeeble the muscles, and derange the whole vital machinery. Fretting, fidgeting, ennui, and anxiety are among the most common causes of disease On the other hand, high aspiration and enthusiasm help gestion and respiration, and send an increased supply of vital energy to all parts of the body. Courage and work invigorate the whole system, and lift one into a purer atmosphere, above the reach of contagion. The lazy groan most over their “arduous duties," while earnest workers talk little about the exhausting labors of their profession. Of all creatures, the sloth would seem to be the most worried and worn.-B. G. Northrop, Conn

THE cabin fittings of the new Cunard steamer Gallia are being made in Japan. It is stated that the work will be cheaper and better than if made in England.

THE PHILADELPHIA LAWN MOWERS.

rust brown. It transforms in the autumn, within the decay. We illustrate herewith two forms of an improved lawn ing wood upon which it feeds, to a bluish white pupa, in mower, which is claimed to run easily, work efficiently, and which the front pair of legs of the future beetle are thrown the strongly and durably constructed. Fig. 1 represents forward under the head, and the horns are plainly visible on made, suitable for large and small lawns. The construction will be readily understood from the engraving. Fig. 2 is a new 15 inch mower, with $81 / 2$ inch driving wheels, and $6 \frac{1}{2}$
inch wiper or revolving knife cylinder. It weighs $51 \mathrm{lbs}$.,

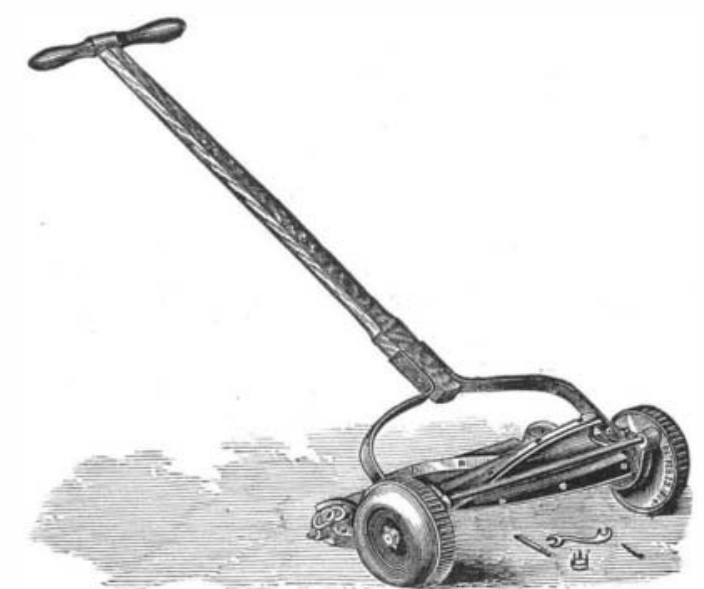

THE PHILADELPHIA LAWN MOWER.-Fig. 1.
ASTRONOMTCAI NOTES.

Penn Yan, N. Y., Saturday, April 20, 1878

The following calculations are adapted to the latitude of New York city, and are expressed in true or clock time, being for the date given in the caption when not otherwise stated.

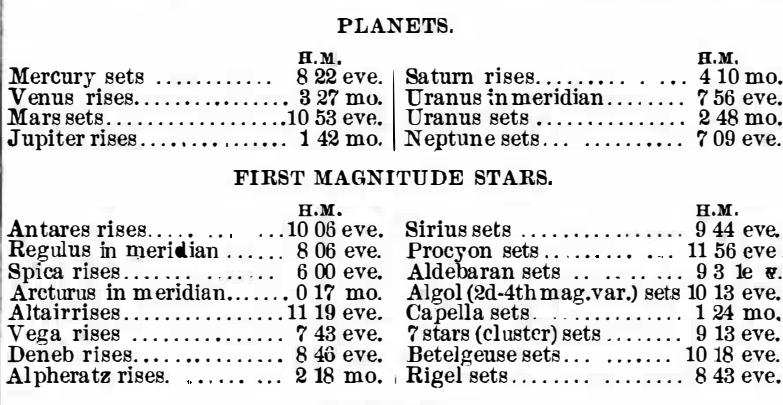
REMARKS.

Venus, Jupiter, and Saturn are now morning stars. Mercury and Mars are evening stars. Mercury sets $1 \mathrm{~h} .38 \mathrm{~m}$ after the sun, and just as twilight ends, the sun at that tim being $18^{\circ}$ below the horizon. He is stationary April 26 Jupiter will be morning star after April 25; is occulted by uns light for one man, and can be adjusted to cut from $1 / 2$ the moon April 24 in the morning. This rare phenomenon $1 \frac{1}{2}$ inch high. For large open lawns this mower is pecially well suited.

An excellent feature of these machines is that they are taken up by set screws. The weight of the journals can be ranges from 32 lbs. to 50 lbs. Large mowers adapted to be

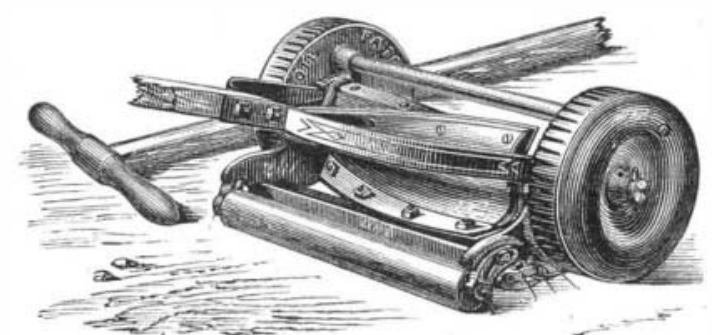

THE PHILADELPHIA LAWN MOWER.-FIg. 2.

drawn by a horse range from 315 to 450 lbs. For further information address the manufacturers, Messrs. Graham Emlen \& Passmore, 631 Market St., Philadelphia, Pa.

\section{THE HORN BUG.}

\section{BY PROFESSOR C. Y. BIL.}

One of the most common and most interesting American eetles met with at this season of the year in wooded regions is what is popularly called the " horn bug," and entomologically known as Passalus cornutus, Fabr. . Few insects are
more familiar to the Western farmer's boy, who finds it in every old stump or under every old log that he digs into or turns over. The polished, rather elegant creature, with its low, clumsy motions, makes a very good plaything for little hitched by means of a thread to the curved horn on its head. hitched by means of a thread to the curved horn on its head.
How few of them, however, ever interest themselves in its development, or ask themselves where it comes from and how it grows! When disturbed, this beetle makes known its displeasure by a peculiar half squeaking, half hissing sound, adomen against the inside of the hard wing covers.
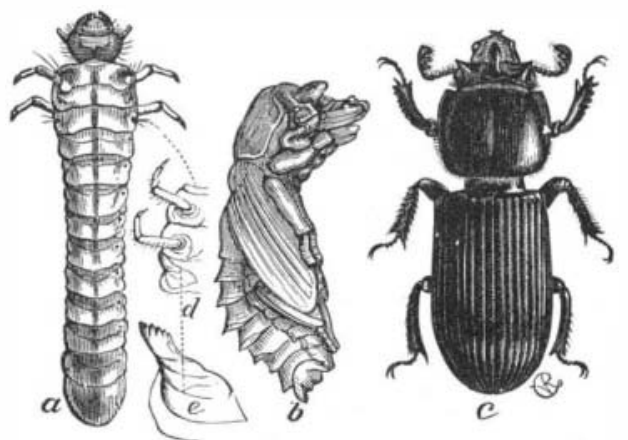
pproach in this latitude is at $6 \mathrm{~h} .25 \mathrm{~m}$. morning, at which time Jupiter is about $38^{\prime}$ north of the moon. As twilight begins at $3 \mathrm{~h}$. $29 \mathrm{~m}$. morning, perhaps $4 \mathrm{o}^{\prime}$ clock in the morning will be the best time to observe them, at which time their relative positions will vary but little from those given above. Jupiter is at his western quadrature April 25.

\section{New Mechanical Inventions.}

Mr. T. H. Thompson, of Benson, Minn., has invented Trace Trimming and Creasing Machine, which trims, edges, creases, and smooths harness traces in a single operation, by means of a combination of adjustable rollers and cutters.

Mr. F. E. Brandis, of Brooklyn, N. Y., has invented a Spindle Attachment for Surveyors' Instruments, by which the upper cone on the parallel rods of the tripod is done away with, the vertical distance between the center of the ball and socket joint and the bubble is reduced, and the biasing of the center by the parallel screws dispensed with.
An improvement in Safe Bolt Works has been devised by Mr. Mayer Adler, of New York city. In this arrangement vertical sliding and lateral swinging bolts are jointly operated by coupled pivot rods of the lock, which are extended beyond the lock or drawn back by a key socket and cam, actuated by a lug on the key.

A Balanced Slide Valve, invented by Mr. R. G. Bishop, of Chetopah; Kan., is claimed to be not liable to leak or wear out. A center chest cast on the cylinder is connected with side chests. At both ends of the center chest are lateral chambers, opening by ports into the cylinder, for inducting nd educting the steam, the lateral ports opening also sidenected by transverse screw bolts, are reciprocated.

An improved Horse Power, patented by Mr. Squire Thomas, of Junction City, Oregon, consists of a wheel placed in a movable frame and arranged to roll upon the ground, and in a stationary frame containing gearing driven by the raveling wheel, as it is drawn around it by the horses. Mr. Norman Bly, of Crown Point, N. Y., has invented an improved machine for Reducing Wood to Paper Pulp. It consists of a series of thick circular saws and a single thin guide saw of slightly larger diameter, mounted on a mandrel or shaft and driven by a suitable motor.

An improved Lifting Jack has been invented by Mr. J. B. Fayette, of Oswego, N. Y. It combines tw o essential points, the application of power in a direct line with the slides, thus obviating side strain, and lifting the object the fullthrow of the machine.

Mr. G. B. Markle, of Jeddo, Pa., has invented a machine for Breaking Coal and similar substances. The breaker plates are each made in two parts, dovetailed together, to enable the inner toothed'parts to be readily removed. Power is applied by eccentric arms from the shaft to one of the plates, which is rearwardly inclined, and the other plate is adjustable, by means of set screws, so as to regulate the fineness to which the coal is broken.

Mr. J. A. Morrison, of Karns City, Pa., has patented a
combined Elevator and Clamp for the Sucker Rods of Oil us. $-a$, larva; $b$, pupa;,$e$, beetle; $\boldsymbol{d}$, ste
atropbied third leg; $e$, this last enlarged. Common as is the beetle, its larva and pupa are but seldom combined Elevator and Clamp for the Sucker Rods of Oil \begin{tabular}{l|l} 
lished in the fourth and fifth Reports on the Insects of Mis- & Wells, intended to dispense with the use of sucker rod \\
wrenches, to retain the rods steadily in position, and protect
\end{tabular} souri. The eggs are deposited under the loose bark of de- their threaded ends. It consists of a main lever, forked at caying logs, are ovoid, and 0.12 inch long. The shell is its lower end, and having a clamp recessed to receive the smooth, fiexile, but tough, and of various shades of olive shoulder or neck of the rod, which clamp is fulcrumed in green. The eggs hatch in July, and the larva acquires full the fork. A safety slide is guided along the shank of the growth in the amazingly short period of six weeks. The main lever, and may be lowered over
larva is very exceptional, in that it possesses but two pairs of the rod to protect and secure it.

of well developed thoracic legs, the third pair being so rudimentary as to be almost invisible. The form is, in other re mentary as to be almost invisible. The form is, in other re-
spects, grub-like, the thoracic joints being slightly enlarged A new form of Windmill, invented by Mr. G. B. Dean, of Lamoille, Ill., is constructed almost entirely of iron, with the exception of the wheel and vane, and so as to dispense with the use of heavy and complicated turn tables, oil boxes. d flattened. The color is bluish white, except the head, which is a light $\mid$ and joints. 